\title{
CDC27 Facilitates Gastric Cancer Cell Proliferation, Invasion and Metastasis via Twist-Induced Epithelial-Mesenchymal Transition
}

\author{
Yongfan Xin ${ }^{a} \quad$ Shili Ning ${ }^{b} \quad$ Liang Zhang $^{c} \quad$ Ming Cuid \\ aDepartment of Interventional Therapy, the First hospital of Shanxi Medical University, Taiyuan, \\ bDepartment of Acute Abdominal Surgery, the Second Affiliated Hospital of Dalian Medical \\ University, Dalian, 'Department of Interventional Therapy, the Second Affiliated Hospital of Dalian \\ Medical University, Dalian, dDepartment of Emergency, the Second Affiliated Hospital of Dalian \\ Medical University, Dalian, China
}

\section{Key Words}

CDC27 • Gastric Cancer • Twist • EMT

\begin{abstract}
Background/Aims: Lymph node metastasis is the primary cause of cancer-related death among patients with gastric cancer (GC), and cell division cycle 27 (CDC27) promotes the metastasis and epithelial-mesenchymal transition in many cancers. Till now, the mechanisms underlying CDC27-induced the epithelial-mesenchymal transition (EMT) of GC are still unclear. Methods: We analyzed the expression levels of CDC27 and EMT-related biomarkers using immunohistochemistry and Western blot in 60 cases of GC tissues, and then GC cells with CDC27 shRNAs or plasmids were subjected to in vitro and in vivo assays, including CCK8, wound healing and transwell assays. Results: The CDC27 expression was obviously increased in GC tissues, and significantly correlates with EMT-related biomarkers, lymph node metastasis and poor 5-year overall survival. Additionally, in vitro and in vivo assays demonstrated that silencing of CDC27 expression effectively inhibited GC cell proliferation, invasion and metastasis. Conversely, CDC27 overexpression led to the opposite results. Finally, we demonstrated that Twist shRNA inhibited CDC27-meditated invasion and EMT of GC cells. Conclusion: CDC27 facilitates gastric cancer cell proliferation, invasion and metastasis via Twist-induced EMT; thus, this study offered a new therapy method for GC patients.
\end{abstract}

(C) 2018 The Author(s)

Published by S. Karger AG, Basel

Y.Xin and S. Ning contributed equally to this work.

Liang Zhang

and Ming Cui 


\section{Cellular Physiology Cell Physiol Biochem 2018;50:501-511 \begin{tabular}{l|l|l} 
and Biochemistry & $\begin{array}{l}\text { DOI: 10.1159/000494164 } \\
\text { Published onlIne: 11 October } 2018\end{array}$ & $\begin{array}{l}\text { @ } 2018 \text { The Author(s). Published by S. Karger AG, Basel } \\
\text { www.karger.com/cpb }\end{array}$ \\
\hline
\end{tabular}}

Xin et al.: CDC27 Induces EMT via Twist in Gastric Cancer

\section{Introduction}

Gastric cancer is the leading cause of cancer-related death among most common malignancy [1-3]. The prognosis in GC patients is unsatisfactory, especially those with advanced TNM stages. The main reason is the occurrence of local and systemic metastasis [46]. However, the molecular mechanisms underlying GC metastasis remain largely unknown. Investigating the mechanisms and regulatory networks of GC metastasis will contribute to the identification of novel biomarkers and therapeutic targets of GC.

EMT has a critical role in invasive and metastatic potential of different types of cancers [79]. During EMT, the expression of some epithelial cell markers, such as E-cadherin decreases, while the expression of mesenchymal cell markers increases, such as twist and vimentin [10$12]$. Besides, increasing reports revealed that CDC27 expression was deregulated in varies of cancers, including breast cancer, and colorectal cancer [13-15]. Feng Z et al. reported that mir218-2 promotes glioblastomas growth, invasion and drug resistance by targeting CDC27, and that CDC27 expression may be a significant indicator [16]. Accumulating evidence indicates CDC27 may be involved in the invasion and metastasis of gastric cancer cells. However, to our knowledge, the mechanisms of CDC27 in metastasis of gastric cancer remain unclear.

In the present study, we analyzed the expression levels of CDC27 and EMT-related biomarkers using immunohistochemistry and Western blot in 60 cases of GC tissues, and then GC cells with CDC27 silencing or over-expression were subjected to in vitro and in vivo assays.

\section{Materials and Methods}

\section{Clinical specimens}

Sixty cases of GC tissues and adjacent non-tumor tissues were collected from GC patients who received surgical treatments between 2012 and 2017 in the Second Affiliated Hospital of Dalian Medical University (Dalian, China). The age range of the patients with GC was 36-79 years old (mean age, 60 years old), with males, 44 and females, 16 . None of the patients received chemotherapy prior to surgical treatment. The clinical samples were collected with informed consent from all patients. The specimens were stored in liquid nitrogen prior to being subjected to further experiments. The protocols were approved by the Institutional Research Ethics Committee of the Second Affiliated Hospital of Dalian Medical University (Dalian, China).

\section{Cell culture}

The human gastric cancer cell lines (AGS, SNU216, SGC7901, MKN45, MGC803 and KATO-III) and normal gastric epithelial GES-1 cells were purchased from American Type Culture Collection (Manassas, VA, USA) and the Cell Bank of Type Culture Collection of the Chinese Academy of Sciences (Shanghai, China). The cells were cultured in RPMI1640 medium (Gibco; Thermo Fisher Scientific, Inc., Waltham, MA, USA) supplemented with 10\% fetal bovine serum (Gibco; Thermo Fisher Scientific, Inc.), $100 \mathrm{mg} / \mathrm{ml}$ penicillin and $100 \mathrm{mg} / \mathrm{ml}$ streptomycin. All cell cultures were maintained in a humidified atmosphere with 5\% CO2 at $37^{\circ} \mathrm{C}$.

\section{Immunohistochemistry (IHC)}

Paraffin sections $(5 \mu \mathrm{m})$ of tissues were deparaffinized and dehydrated with graded ethanol. After blocking the endogenous peroxidase with $3.0 \% \mathrm{H}_{2} \mathrm{O}_{2}$, slides were incubated with citric acid buffer to retrieve antigen by heating in $120^{\circ} \mathrm{C}$ for $15 \mathrm{~min}$. The slides were then blocked with $5 \%$ BSA (Sigma, St. Louis, MO, USA) for $1 \mathrm{~h}$ and incubated with related primary rabbit monoclonal antibody (Santa Cruz Biotechnologies, Dallas, TX, USA) overnight at $4^{\circ} \mathrm{C}$. After that, slides were washed with PBS and further incubated with biotinylated second antibody for $15 \mathrm{~min}$ at room temperature. Finally, the slides were stained using the VECTASTAIN Elite ABC HRP kit and DAB reagents. For negative control, PBS was used instead of primary antibody. 


\section{Cellular Physiology Cell Physiol Biochem 2018;50:501-511 \\ \begin{tabular}{ll|l} 
DOI: 10.1159/000494164 & $\begin{array}{l}\text { O 2018 The Author(s). Published by S. Karger AG, Basel } \\
\text { www.karger.com/cpb }\end{array}$
\end{tabular}}

Xin et al.: CDC27 Induces EMT via Twist in Gastric Cancer

\section{IHC evaluation}

Briefly, the positivity percentage was scored as 0 (0-10\%), $1(11-25 \%), 2$ (26-50\%), $3(51-75 \%)$, and 4 (76-100\%). The staining intensity was scored as 0 (no immunoreactivity), 1 (weakly stained), 2 (moderate stained), and 3 (strong stained). The final IHC score (IHCS) was weighted by multiplying the intensity score with percentage score (range, $0-12$ ). Patients were classified into a low expression group (IHCS $\geqslant 6$ ) and a high expression group (IHCS $<6$ ) according to the IHCS.

\section{Western blot analysis}

RIPA lysis solution and phenylmethylsulfonyl fluoride solution were added to cells, which were then centrifuged at $12,000 \mathrm{rpm}$ for $15 \mathrm{~min}$ at $4^{\circ} \mathrm{C}$. The extracted total protein was subjected to sodium dodecyl sulfate-polyacrylamide gel electrophoresis and transferred onto a polyvinylidene difluoride membrane, which was subsequently immersed in 5\% skim-milk blocking solution for $2 \mathrm{~h}$. The membrane was then incubated with a rabbit anti-human monoclonal antibody and mouse anti-human GAPDH monoclonal antibody (1:1, 000; Santa Cruz Biotechnologies, Dallas, TX, USA) separately at $4^{\circ} \mathrm{C}$ overnight, before being exposed to a secondary antibody at $25^{\circ} \mathrm{C}$ for $1 \mathrm{~h}$. Finally, chemiluminescence reagent was added. Relative expression was normalized to GAPDH levels, which were analyzed using Quantity One software (Bio-Rad Laboratories, Hercules, CA, USA).

\section{Transfection}

Cells were transfected with CDC27 shRNA using Lipofectamine RNAi reagent (Thermo Fisher Scientific, Rockford, IL, USA). CDC27 mRNA sequences were obtained from Genebank to design primers. Then PCR amplification was performed and the PCR product was subjected to 1\% agarose gel (SeaKem GTG; FMC BioProducts, Rockland, Maine) electrophoresis. The recovered CDC27 fragment and vector PCDNA3.1 were digested with HindIII and XhoI (Takara Shuzo Co, Japan), and the gel was recovered by electrophoresis, and then ligated with T4 DNA ligase (New England Biolabs, Beverly, MA) overnight at $4^{\circ} \mathrm{C}$. At last, the ligation product was transformed into DH5a. After the single clones were picked, the extracted plasmids were identified and sequenced by double digestion. Then cells were transfected with PCDNA3.1-CDC27 by Lipofectamine-2000 (Thermo Fisher Scientific, Rockford, IL, USA). The protein expression of CDC27 was assessed by Western blot analysis.

\section{Wound healing and transwell assays}

For the wound healing migration assay, cells were plated in 24-well plates and allowed to attach overnight. Confluent monolayer cells were scraped using $10 \mu \mathrm{l}$ pipette tips. At the indicated time points ( 0 and $48 \mathrm{~h}$ ), the wound areas were photographed under a microscope (Olympus, Tokyo, Japan). For the transwell invasion assay, $1 \times 10^{5}$ cells were added into the upper chamber of an insert precoated with matrigel (Costar, Cambridge, MA, USA). And $100 \mu \mathrm{l}$ medium containing 20\% FBS were added to the lower part of the chamber. After $24 \mathrm{~h}$ of incubation, the invaded cells were fixed with methanol and stained with eosin solution (Beyotime Company, Shanghai, China).

\section{Cell proliferation assay}

The transfected cells were seeded into 96-well plates, in DMEM medium supplemented with 10\% FBS, at a density of 2,000 cells/well, and cultured at $37^{\circ}$ C. At the end of each experiment, a 10- $\mu$ l Cell Counting kit-8 (CCK-8) solution was added to each well and subsequently incubated for $2 \mathrm{~h}$ at $37^{\circ} \mathrm{C}$. The relative optical density (OD) level was evaluated at an absorbance of $450 \mathrm{~nm}$ and normalized to that of the controls using a standard microplate reader (Thermo Fisher Scientific, Inc.).

\section{Animal experiment}

Balb/c nude mice were used under the animal laboratory conditions according to the approved guidelines of the Institutional Animal Care and Use Committee of the Second Affiliated Hospital of Dalian Medical University (Dalian, China) and were performed on the basis of the institutional guidelines. Human tumour xenograft models were created by subcutaneous injection of SGC7901 cells (sh-NC/sh-CDC27) or AGS cells (Vector/CDC27), and then grown for 5 weeks. The size of the generated tumour was evaluated 


\section{Cellular Physiology Cell Physiol Biochem 2018;50:501-511 \begin{tabular}{ll|l} 
and Biochemistry Published onlIne: 11 October 2018 & $\begin{array}{l}\text { (c) } 2018 \text { The Author(s). Published by S. Karger AG, Basel } \\
\text { www.karger.com/cpb }\end{array}$ \\
\hline
\end{tabular}}

Xin et al.: CDC27 Induces EMT via Twist in Gastric Cancer

using a tumour volume calculation formula of $(\mathrm{W} \times \mathrm{W} \times \mathrm{L}) / 2$. Lung metastatic models were developed by slow injection into the tail vein of mouse. Mice were sacrificed after 5 weeks, and tumours were removed for RNA and protein extraction, haematoxylin and eosin (H\&E) staining or IHC staining.

\section{Statistical analysis}

Data were analyzed using SPSS software 19.0 version (IBM Corp., Armonk, NY, USA) or GraphPad Prism software (version 5.0; GraphPad Software, Inc., La Jolla, CA, USA) and presented as the mean \pm standard deviation. Comparisons between two groups were assessed using a non-paired Student's t-test. Comparison among three groups was performed by one-way analysis of variance, and differences between two groups were determined by Newman-Keuls multiple comparison unless the data were not normally distributed, in which case a Kruskal-Wallis test and Nemenyi test were applied. Correlation analysis was conducted using Pearson's or Spearman's correlation. The $\chi 2$ test was performed to analyze the association between protein expression and clinicopathological indicators. Survival curves were generated using the KaplanMeier estimator method, which were then compared using the log-rank test. Overall survival was defined as the time between the date of initial therapy and the final follow-up or the time of patient mortality due to any cause. $\mathrm{P}<0.05$ was considered as a statistically significant difference.

\section{Results}

CDC27 expression and its association with EMT-related biomarkers in GC samples

Firstly, we detected the expression of CDC27 protein in 60 cases of GC tissues and adjacent normal tissues using Western blot analysis and IHC. We found that CDC27 protein has a significantly higher relative expression level compared with that in adjacent normal tissues $(P<0.001$, Fig. 1A). Furthermore, Twist and Vimentin also had higher relative expressions in GC tissues than those in adjacent normal tissues (both $P<0.001$, Table 1). However, E-cadherin expression was significantly relatively lower in GC tissues than that in adjacent normal tissues $(P<0.001$, Table 1$)$. And then, the clinicopathological analysis

Fig. 1. Expression and significance of CDC27 and EMT biomarkers in gastric cancer tissues and normal gastric tissues. (A) Western blot assay was used to compare CDC27 expression in three representative gastric cancer tissues (C.T.) and normal tissues (N.T.) from different patients. GAPDH was used as internal control. (B) The average staining scores of CDC27 expression in GC patients with or without metastasis. (C-F) Survival curves of gastric cancer patients with CDC27, E-cadherin, Twist or Vimentin expression. ${ }^{*} \mathrm{P}<0.05$ v.s. non-metastasis. Bars show the means \pm SD of three independent experiments.

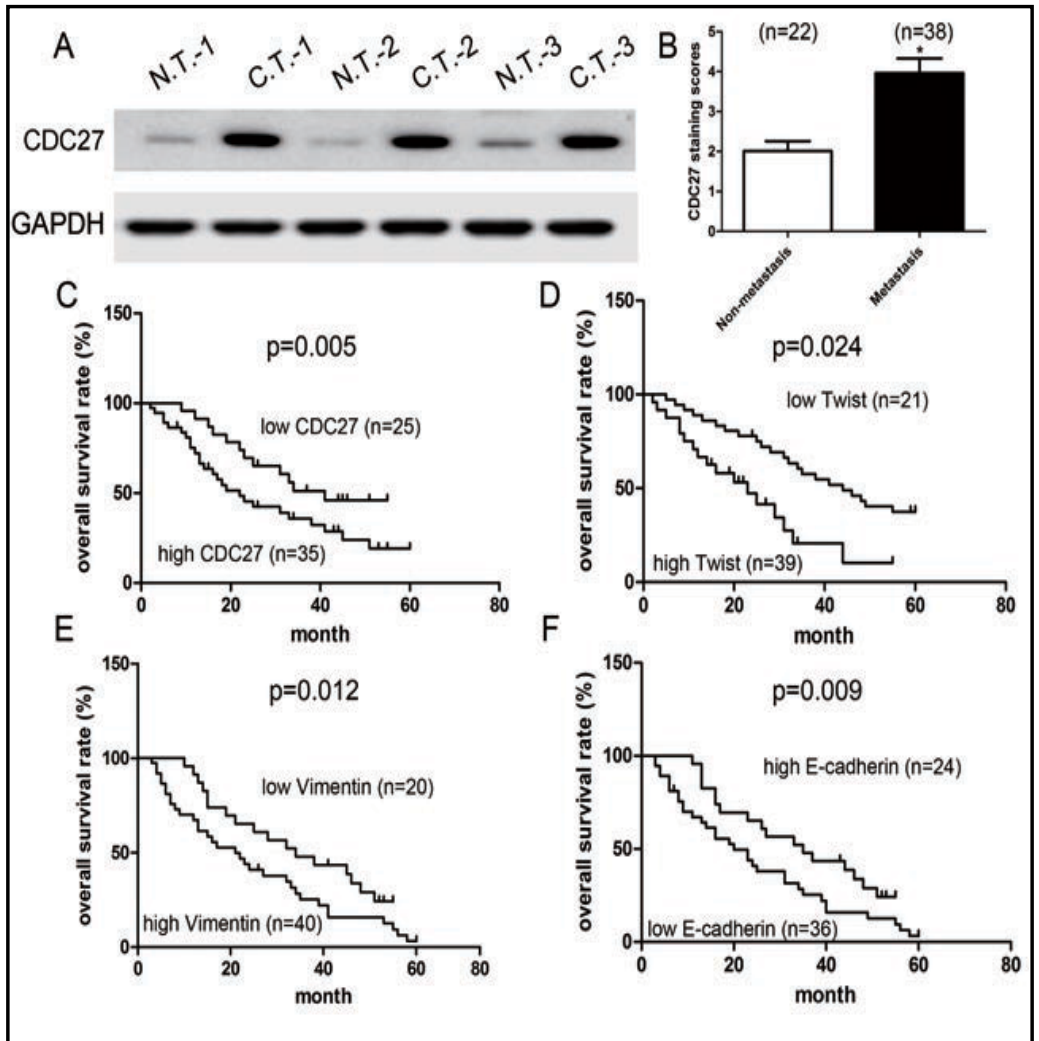




\section{Cellular Physiology Cell Physiol Biochem 2018;50:501-511 \begin{tabular}{ll|l} 
DOI: 10.1159/000494164 & $\begin{array}{l}\text { O 2018 The Author(s). Published by S. Karger AG, Basel } \\
\text { www.karger.com/cpb }\end{array}$ \\
\hline
\end{tabular}

from 60 cases of GC tissues suggested that the relative expressions of CDC27, E-cadherin, Twist and Vimentin proteins obviously correlated with T stage, pTNM stage and lymph node metastasis, respectively (all $P<0.05$, Table 2 ). It should be noted that patients with lymph node metastasis had significantly higher relative CDC27 expression levels than those without lymph node metastasis $(P<0.001$, Fig. 1B), indicating that CDC27 may have an important role in GC metastasis. Besides, relative CDC27 expression was observed to markedly correlate with the relative expression of E-cadherin, Twist and Vimentin $(P<0.001, P<0.001, P=0.046$, respectively; Table 3). Finally, our survival analysis exhibited that positive expression of CDC27, Twist or Vimentin had a negative relationship with five-year overall survival of post-operative 60 cases of GC patients $(P=0.005, P=0.024, P=0.012$, respectively; Fig. 1C-E). However, positive expression of E-cadherin had a positive relationship with overall survival of post-operative GC patients ( $P=0.009$, Fig. $1 \mathrm{~F})$.

\section{CDC27 facilitates GC cell metastasis}

To explore the role of CDC27 in the metastasis of gastric cancer, the expression level of CDC27 was analyzed in 6 kinds of GC cell lines, including AGS, SNU216, SGC7901, MKN45, MGC803 and KATO-III, and normal gastric epithelial GES-1 cells. We found that CDC27 showed the highest expression in SGC7901 and SNU216 cells, and had the lowest expression in AGS cells and GES- 1 cells $(P<0.05$, Fig. $2 A)$. Accordingly, SGC7901 and SNU216 cells were used for subsequent transfection
Table 1. Expressions of CDC27, E-cadherin, Twist and Vimentin in gastric cancer and normal tissues

\begin{tabular}{lccc}
\hline Proteins & cancer tissues & normal tissues & P-value \\
\hline CDC27 & & & \\
Positive & 35 & 19 & 0.003 \\
Negative & 25 & 41 & \\
$\begin{array}{l}\text { E-cadherin } \\
\text { Positive }\end{array}$ & 24 & 45 & $<0.001$ \\
Negative & 36 & 15 & \\
Twist & & & \\
Positive & 39 & 18 & $<0.001$ \\
Negative & 21 & 42 & \\
Vimentin & & & \\
Positive & 40 & 20 & $<0.001$ \\
Negative & 20 & 40 & \\
\hline
\end{tabular}

Table 2. Correlation between CDC27, E-cadherin, Twist and Vimentin expression and clinicopathological features in gastric cancer

\begin{tabular}{|c|c|c|c|c|c|c|c|c|c|c|c|c|c|}
\hline \multirow{2}{*}{ Indicators } & \multirow{2}{*}{$\mathrm{n}$} & \multicolumn{3}{|c|}{ CDC27 } & \multicolumn{3}{|c|}{ E-cadherin } & \multicolumn{3}{|c|}{ Twist } & \multicolumn{3}{|c|}{ Vimentin } \\
\hline & & + & - & P-value & + & - & P-value & + & - & P-value & + & - & P-value \\
\hline \multicolumn{14}{|l|}{ Age (year) } \\
\hline$\geq 60$ & 41 & 23 & 18 & \multirow{2}{*}{0.606} & 15 & 26 & \multirow{2}{*}{0.428} & 25 & 16 & \multirow{2}{*}{0.337} & 25 & 16 & \multirow{2}{*}{0.169} \\
\hline$<60$ & 19 & 12 & 7 & & 9 & 10 & & 14 & 5 & & 15 & 4 & \\
\hline \multicolumn{14}{|l|}{ Gender } \\
\hline Male & 44 & 26 & 18 & \multirow{2}{*}{0.694} & 16 & 28 & \multirow{2}{*}{0.340} & 27 & 17 & \multirow{2}{*}{0.327} & 29 & 15 & \multirow{2}{*}{0.837} \\
\hline Female & 16 & 9 & 7 & & 8 & 8 & & 12 & 4 & & 11 & 5 & \\
\hline \multicolumn{14}{|c|}{ Tumor size $(\mathrm{cm})$} \\
\hline$\geq 5$ & 36 & 23 & 13 & \multirow{2}{*}{0.285} & 9 & 27 & \multirow{2}{*}{0.004} & 21 & 15 & \multirow{2}{*}{0.185} & 23 & 13 & \multirow{2}{*}{0.576} \\
\hline$<5$ & 24 & 12 & 12 & & 15 & 9 & & 18 & 6 & & 17 & 7 & \\
\hline \multicolumn{14}{|c|}{ Lauren's classification } \\
\hline Diffuse & 16 & 9 & 7 & \multirow{2}{*}{0.843} & 6 & 10 & \multirow{2}{*}{0.812} & 9 & 7 & \multirow{2}{*}{0.392} & 8 & 8 & \multirow{2}{*}{0.099} \\
\hline Intestinal & 44 & 26 & 18 & & 18 & 26 & & 30 & 14 & & 32 & 12 & \\
\hline \multicolumn{14}{|c|}{ Lymphatic vessel invasion } \\
\hline Yes & 28 & 17 & 11 & \multirow{2}{*}{0.726} & 10 & 18 & \multirow{3}{*}{0.526} & 21 & 7 & & 20 & 8 & \\
\hline No & 32 & 18 & 14 & & 14 & 18 & & 18 & 14 & 0.129 & 20 & 12 & 0.464 \\
\hline T stage & & & & & & & & & & & & & \\
\hline $\mathrm{T}_{1}+\mathrm{T}_{2}$ & 29 & 21 & 8 & 0032 & 6 & 23 & 0003 & 24 & 5 & 0005 & 23 & 6 & 0,045 \\
\hline $\mathrm{T}_{3}+\mathrm{T}_{4}$ & 31 & 14 & 17 & 0.032 & 18 & 13 & 0.003 & 15 & 16 & & 17 & 14 & 0.045 \\
\hline pTNM stag & & & & & & & & & & & & & \\
\hline $\mathrm{I}+\mathrm{II}$ & 33 & 23 & 10 & 0048 & 9 & 24 & 0.026 & 26 & 7 & 0013 & 27 & 6 & 0006 \\
\hline III + IV & 27 & 12 & 15 & 0.048 & 15 & 12 & $0.0<6$ & 13 & 14 & 0.013 & 13 & 14 & 0.006 \\
\hline Lymph noc & met & stas & & & & & & & & & & & \\
\hline Yes & 38 & 29 & 9 & $<0001$ & 10 & 28 & 0.005 & 29 & 9 & 0016 & 29 & 9 & 0037 \\
\hline No & 22 & 6 & 16 & $<0.001$ & 14 & 8 & 0.005 & 10 & 12 & 0.010 & 11 & 11 & 0.031 \\
\hline
\end{tabular}




\section{$\begin{array}{lll}\text { Cellular Physiology } & \text { Cell Physiol Biochem 2018;50:501-511 } \\ \text { DOI: 10.1159/000494164 } & \text { O 2018 The Author(s). Published by S. Karger AG, Basel }\end{array}$

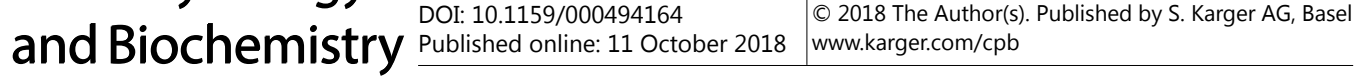 \\ Xin et al.: CDC27 Induces EMT via Twist in Gastric Cancer}

using CDC27 shRNA, and AGS cell lines were selected for CDC27-overexpression. Western blot analysis revealed the endogenous expression of CDC27 protein was obviously silenced by CDC27 shRNA $(P<0.05$, Fig. $2 \mathrm{~B}$ and $\mathrm{C})$, and obviously increased by CDC27 overexpression plasmids $(P<0.05$, Fig. 2 B and $C)$. As shown in Fig. 3 , both the migration and invasion ability of SGC7901 cells that were transfected with the shRNAs targeting CDC27 were significantly impaired, which was identical with those in SNU216 cells $(P<0.05)$. Further, our data revealed CDC27 overexpression reversed the impaired migration and invasion capabilities of gastric cancer cells and increased the migration and invasion cell number in AGS cells $(P<0.05)$. These data indicated that CDC27 facilitated the metastasis of GC cell lines.

\section{CDC27 facilitates GC cell invasion via}

Twist-induced EMT

In order to figure out whether CDC27 enhanced the invasiveness of GC cells via EMT, the EMT biomarkers (E-cadherin, Snail, Twist, and Vimentin) were detected using Western blot analysis. Results showed that the expression of E-cadherin was obviously elevated in CDC27-silenced SGC7901 or SNU216 cells, accompanied by an obvious reduce in the expressions of Vimentin and Twist $(P<0.05$, Fig. 4A and B). However, AGS cells with CDC27 overexpression had opposite effects $(P<0.05$, Fig. $4 \mathrm{C})$. Notably, the expression of Snail was not obviously altered in
Table 3. Correlation of CDC27 with E-cadherin, Twist and Vimentin in gastric cancer tissues

\begin{tabular}{lcccc}
\hline & \multicolumn{2}{c}{ CDC27 } & \multirow{2}{*}{$\chi^{2}$} & \multirow{2}{*}{ P-value } \\
\hline E-cadherin & & & & \\
Positive & 6 & 18 & 18.29 & $<0.001$ \\
Negative & 29 & 7 & & \\
Twist & & & & \\
Positive & 33 & 6 & 31.67 & $<0.001$ \\
Negative & 2 & 19 & & \\
Vimentin & & & & \\
$\begin{array}{l}\text { Positive } \\
\text { Negative }\end{array}$ & 32 & 18 & 3.96 & 0.046 \\
\hline
\end{tabular}

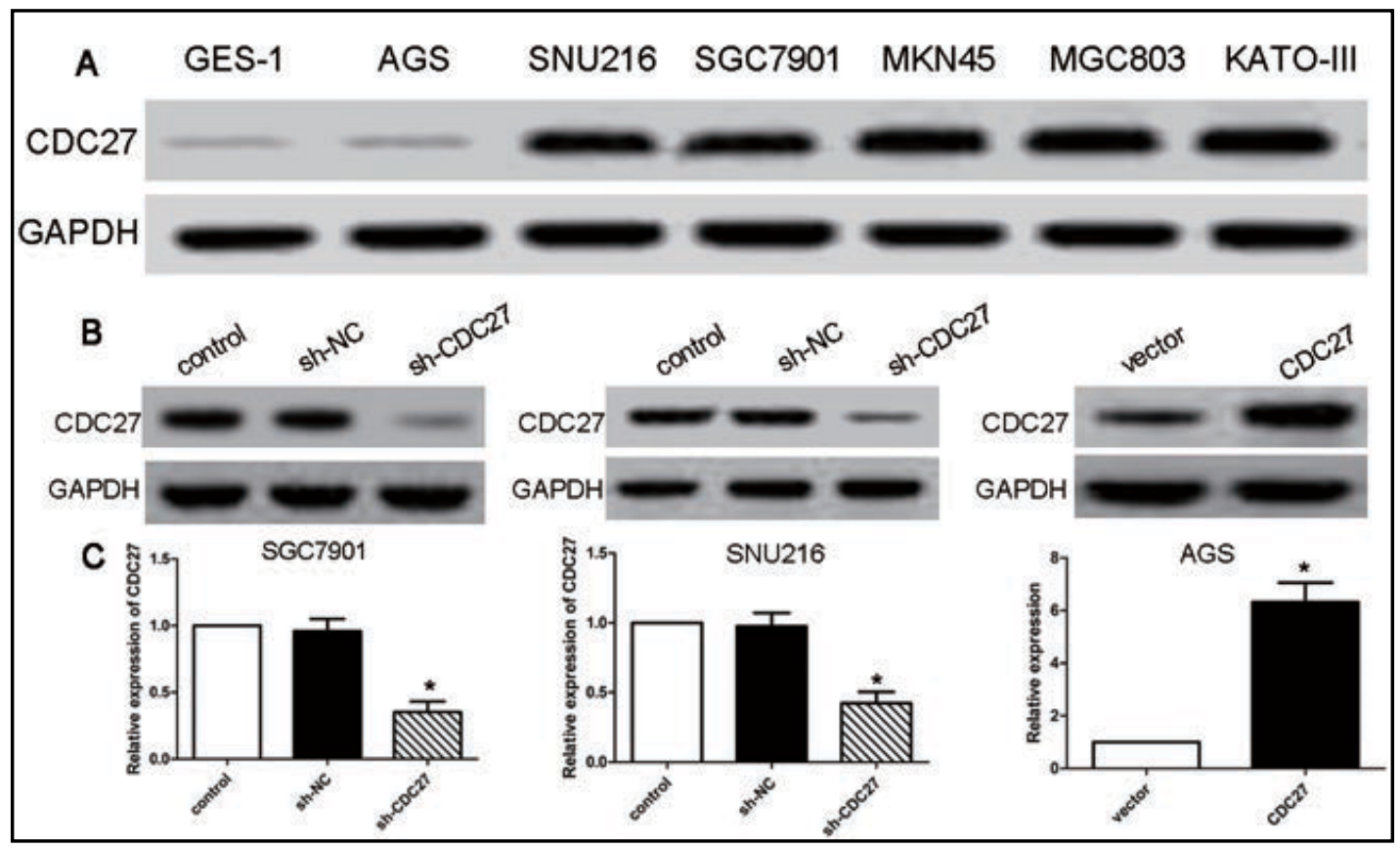

Fig. 2. Expression of CDC27 protein in GC cells and normal gastric cells. (A) Relative expression of CDC27 protein in gastric cancer cell lines (AGS, SNU216, SGC7901, MKN45, MGC803 and KATO-III) and normal gastric epithelial GES-1 cells were measured by Western blot. (B-C) Relative expression of CDC27 protein was detected by Western blot in CDC27-knockdown SGC7901 and SNU216 cells and CDC27 overexpressing AGS cells. GAPDH was used as internal control. ${ }^{*} \mathrm{P}<0.05$ v.s. control or sh-NC. Bars show the means \pm SD of three independent experiments. 


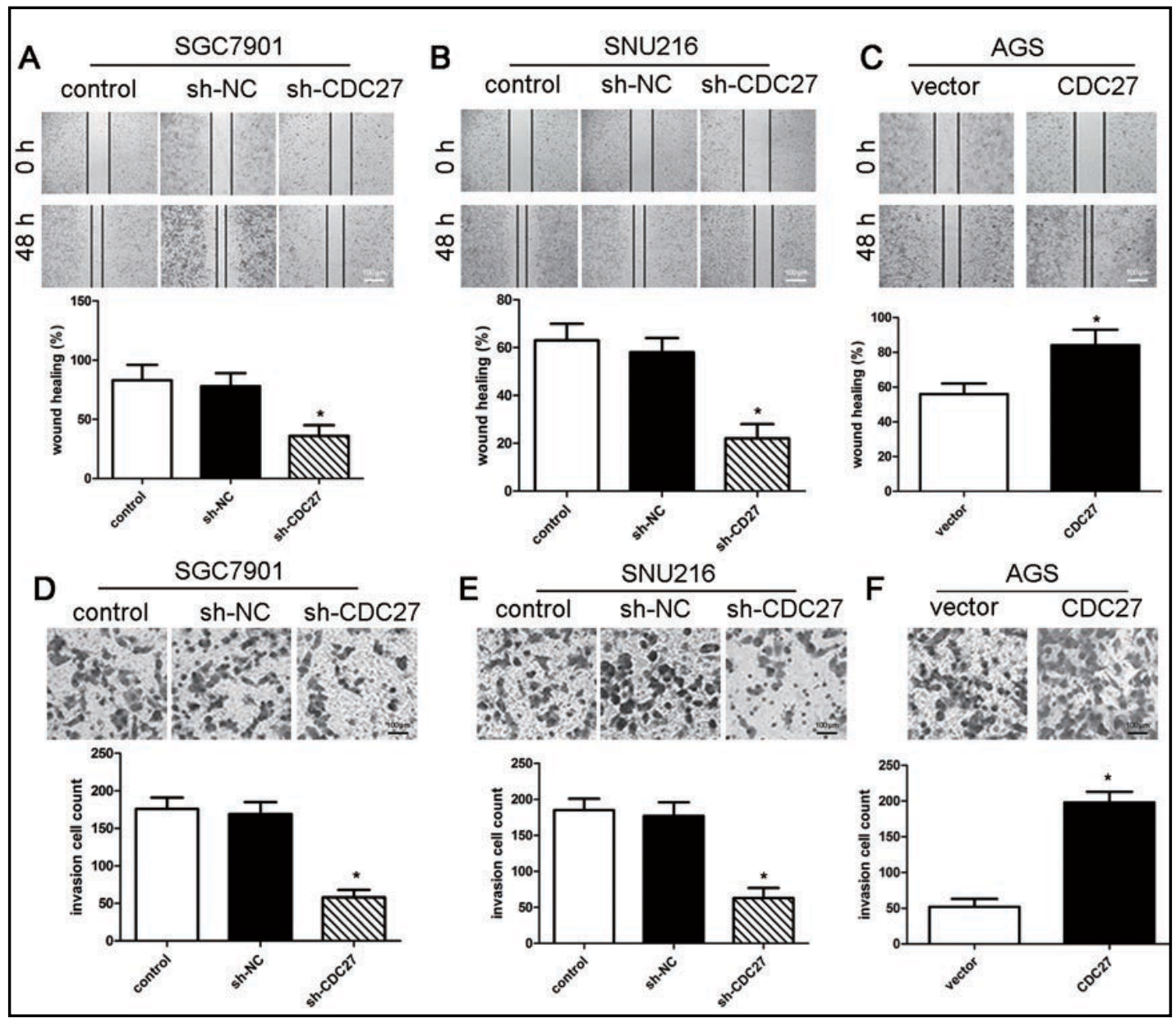

Fig. 3. Effects of CDC27 silencing and overexpression on GC cells migration and invasion. (A-C) Effects of silenced CDC27 expression on migratory ability of SGC7901 and SNU216 cells by wound-healing assay. (D-F) Effects of overexpressed CDC27 on invasive ability of AGS cells by transwell invasion assay. $*$ P $<0.05$ v.s. control or sh-NC. Bars show the means \pm SD of three independent experiments.

SGC7901, SNU216 and AGS cells (Fig. 4A-C). Next, we continued to explore the role of Twist in CDC27-mediated EMT, and found that Twist shRNA reversed CDC27-mediated EMT biomarkers in AGS cells $(P<0.05$, Fig. 4D). As expected, Twist shRNA significantly inhibited the CDC27-mediated invasion of AGS cells $(P<0.05$, Fig. 4E).

\section{CDC27 facilitates GC cell metastasis in vivo}

In this work, six-week-old male BALB/c nude mice were utilized for tumourigenicity. At $24 \mathrm{~h}$ after transfection, SGC7901 cells (sh-NC/sh-CDC27) or AGS cells (Vector/CDC27) were inoculated in nude mouse armpit to construct xenograft tumor model nude mice. Vital signs of nude mice were observed, and the mice were sacrificed in 5th week to extract tumor tissues. According to HE staining, we observed that nude mice containing SGC7901 cells with sh-CDC27 had significantly less lung metastasis nodules than the sh-NC group $(P<0.05$, Fig. 4F). Conversely, nude mice containing AGS cells with CDC27 overexpression had more lung metastasis nodules than the vector control $(P<0.05$, Fig. $4 \mathrm{G})$. In addition, the immunohistochemical analysis revealed that the expression of CDC27 in tumor tissues containing SGC7901 cells with sh-CDC27 was lower compared with the sh-NC group. However, the expression of E-cadherin in tumor tissues containing SGC7901 cells with sh-CDC27 was higher compared with the sh-NC group. As expected, AGS cells with CDC27 overexpression had the inverse effects.

\section{KARGER}




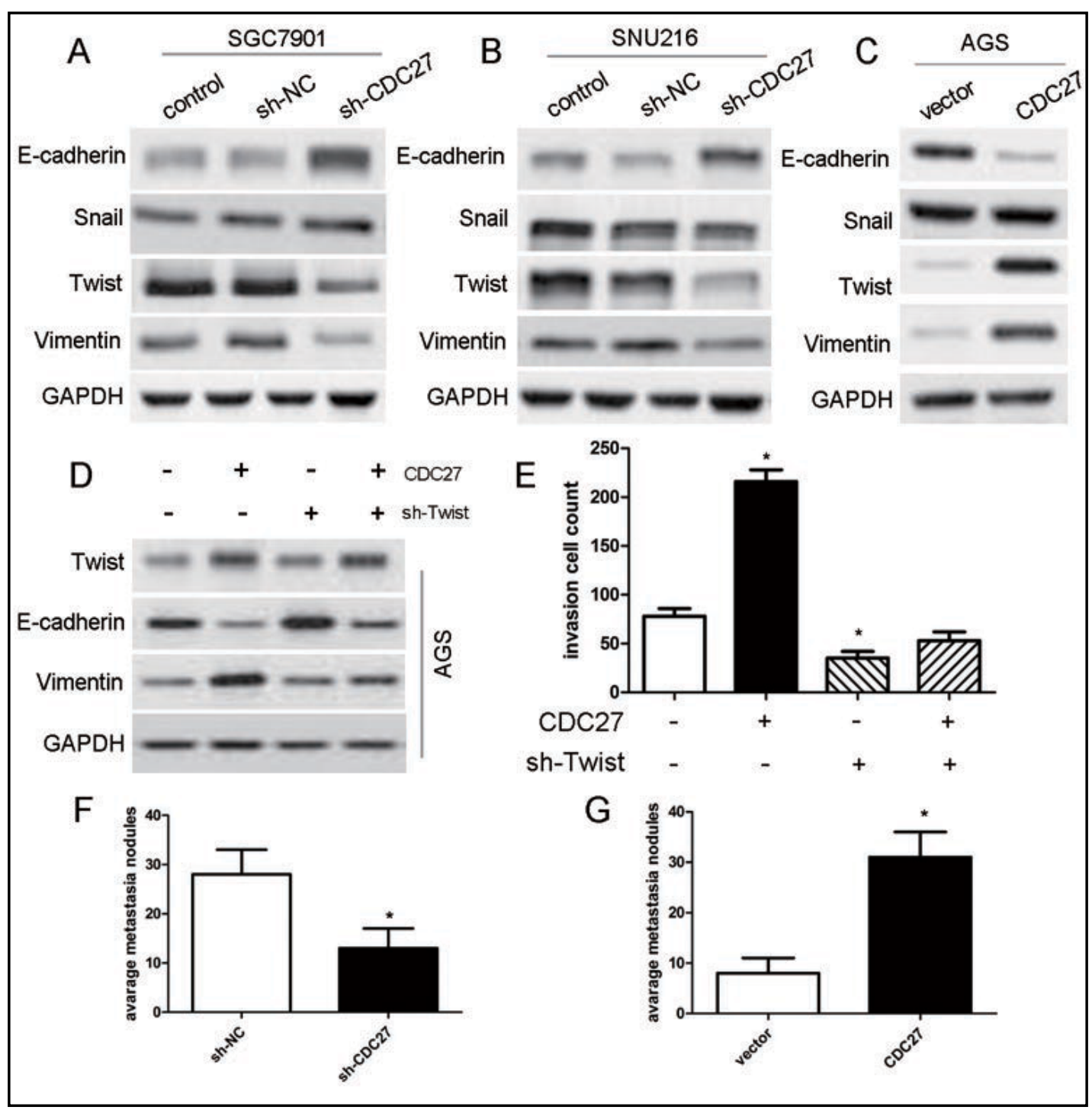

Fig. 4. CDC27 induced cell EMT and invasion via a Twist-dependent mechanism in vitro and in vivo. $(A, B)$ Influences of CDC27-depletion on EMT-related biomarkers in SGC7901 and SNU216 cells. (C) Effects of CDC27 overexpressing on EMT-related markers in AGS cells. (D-E) Insight into a Twist-dependent mechanism of CDC27-meditated cell EMT and invasion, by Western blot and transwell assay. GAPDH was used as internal control. ${ }^{*} \mathrm{P}<0.05$. (F-G) Lung metastatic nodules were observed in HE-stained samples. The number of average lung metastatic nodules was calculated. $* \mathrm{P}<0.05$ v.s. vector or sh-NC. Bars show the means \pm SD of three independent experiments.

\section{CDC27 also promotes GC cell proliferation}

In this work, we investigated the cell proliferation using in-vitro and in-vivo assay to investigate the potential effect of cell proliferation on CDC27-induced migration and invasion. CCK-8 assay revealed that proliferation rates of three GC cells showed significant differences $(P<0.05$, Fig. 5A). Based on in-vitro assay, we further determine the effect of CDC27 on tumor formation using in vivo assay, SGC7901 cells with sh-CDC27 or AGS cells with CDC27 plasmids were inoculated subcutaneously into nude mice respectively. The mice were sacrificed in 5 th week to extract tumor tissues. The tumour volume was calculated based on the formula: volume $\left(\mathrm{mm}^{3}\right)=(\text { short diameter })^{2} \times($ long diameter $) / 2$. As expected, 


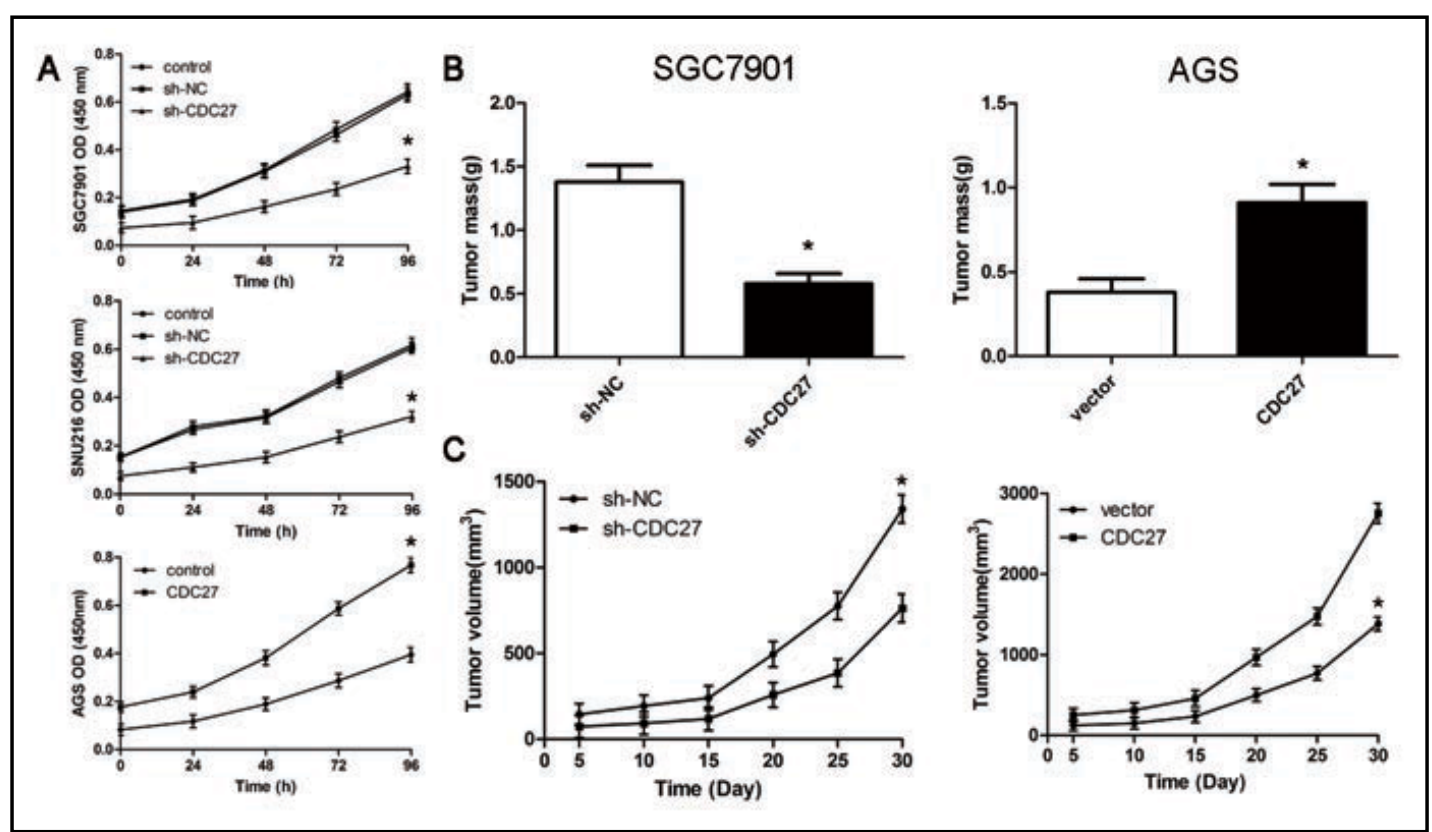

Fig. 5. Effects of CDC27 silencing and over-expression on GC cells proliferation. (A) Effects of CDC27 knockdown and over-expression on the proliferation of GC cells (SGC7901, SNU216 and AGS) in vitro by CCK-8 assay. (B-C) Influences of CDC27 knockdown and overexpression on the tumor formation of GC cells (SGC7901 and AGS) via the subcutaneous injection into nude mice, as well as the measurement of tumor mass and tumor volume. ${ }^{*} \mathrm{P}<0.05$ v.s. vector or sh-NC. Bars show the means \pm SD of three independent experiments.

both weight and the volume of implanted tumors also showed significant differences from their controls $(P<0.05$, Fig. 5B and $\mathrm{C})$. These results indicated that CDC27 promotes GC cell proliferation, which further facilitated GC cell migration and invasion.

\section{Discussion}

CDC27 is a core subunit of anaphase-promoting complex/cyclosome (APC/C), which is required for binding of $\mathrm{CDH} 1$ and $\mathrm{CDC} 20$ to recognize and degrade target substrates. In recent years, CDC27 has been reported to be involved in cell proliferation, migration and invasion in many kinds of cancers $[17,18]$. However, the effect of CDC27 expression on the invasion and metastasis of gastric cancer has not yet been clearly elucidated. In the present study, CDC27 was highly expressed in GC tissues than that in adjacent normal tissues, and obviously correlated with lymph node metastasis, EMT biomarkers and an unfavourable prognosis, suggesting that CDC27 may be involved into the metastasis and EMT of gastric cancer cells.

As known to all, EMT is closely linked to tumor metastasis and invasion. EMT process is featured by loss of cell-cell adhesion mediated by E-cadherin, mesenchymal marker expression and thus increased cell motility and invasiveness [19-21]. In view of the role of CDC27 in the migration and invasion of GC cells, we first examined the effects of CDC27 on the EMT process $[20,21]$. Qiu L et al. reported that CDC27 induces metastasis and invasion in colorectal cancer via the promotion of epithelial-to-mesenchymal transition [15]. Feng $\mathrm{Z}$ et al. also demonstrated that Cdc27 is a target for glioblastomas growth, invasion and drug resistance [16]. Our findings showed that the expression levels of E-cadherin were dramatically increased and that the expression levels of Snail and Twist were correspondingly significantly decreased in the shCDC27 cells. Furthermore, we explored corresponding signalling pathways involved into CDC27-induced EMT. We found that CDC27 facilitated 


\section{Cellular Physiology Cell Physiol Biochem 2018;50:501-511 \begin{tabular}{l|l|l} 
and Biochemistry & $\begin{array}{l}\text { DOI: 10.1159/000494164 } \\
\text { Published onlIne: 1I October } 2018\end{array}$ & $\begin{array}{l}\text { @ } 2018 \text { The Author(s). Published by S. Karger AG, Basel } \\
\text { www.karger.com/cpb }\end{array}$ \\
\hline
\end{tabular}}

Xin et al.: CDC27 Induces EMT via Twist in Gastric Cancer

cells invasion and metastasis via Twist pathway, leading to initiation of EMT. And silencing of Twist expression could reverse this process, suggesting that Twist played an important role in CDC27-induced EMT. Therefore, more signals involved in CDC27-induced EMT in the metastasis of gastric cancer need further identification.

Besides, we explored whether the role of CDC27 in GC cell migration and invasion was attributed to GC cell proliferation. We demonstrated that CDC27 indeed affected gastric cancer cell proliferation to potentially influence cell migration and invasion. On the other hand, there are still many issues that remain to be addressed. For example, current reports showed that CDC27 expressions are involved in different cancers. So, we need to investigate other downstream molecules of CDC27 in more future studies.

\section{Conclusion}

Taken together, our study validated that the high expression of CDC27 was obviously related with GC metastasis and poor prognosis, and CDC27 facilitates gastric cancer cell invasion and metastasis via Twist-induced EMT. Overall, our work may provide a new and useful therapy target for gastric cancer patients.

\section{Disclosure Statement}

The authors have declared that no conflict of interests exists.

\section{References}

1 Siegel RL, Miller KD, Jemal A: Cancer statistics, 2017. CA Cancer J Clin 2017;67:7-30.

$\checkmark 2$ Choi YY, Noh SH, An JY: A randomized controlled trial of Roux-en-Y gastrojejunostomy vs. gastroduodenostomy with respect to the improvement of type 2 diabetes mellitus after distal gastrectomy in gastric cancer patients. PLoS One 2017;12:e0188904.

3 Kojima A, Shimada M, Mikami Y, Nagao S, Takeshima N, Sugiyama T, Teramoto N, Kiyokawa T, Kigawa J, Nishimura R; Sankai Gynecology Study Group: Chemoresistance of Gastric-Type Mucinous Carcinoma of the Uterine Cervix: A Study of the Sankai Gynecology Study Group. Int J Gynecol Cancer 2018;28:99-106.

4 Liu X, Li G, Long Z, Yin J, Zhu X, Sheng W, Huang D, Zhu H, Zhang Z, Cai H, Huang H, Zhao G, Zhou Y, Zhang Z, Wang Y: Phase II trial of preoperative chemoradiation plus perioperative SOX chemotherapy in patients with locally advanced gastric cancer. J Surg Oncol 2018;117:692-698.

5 Laterza MM, Pompella L, Petrillo A, Tirino G, Pappalardo A, Orditura M, Troiani T, Ciardiello F, Di Martino N, De Vita F: Efficacy of a triplet and doublet-based chemotherapy as first-line therapy in patients with HER2-negative metastatic gastric cancer: a retrospective analysis from the clinical practice. Med Oncol 2017;34:186.

6 Chen SC, Kagedal M, Gao Y, Wang B, Harle-Yge ML, Girish S, Jin J, Li C: Population pharmacokinetics of trastuzumab emtansine in previously treated patients with HER2-positive advanced gastric cancer (AGC). Cancer Chemother Pharmacol 2017;80:1147-1159.

7 Huang L, Wu RL, Xu AM: Epithelial-mesenchymal transition in gastric cancer. Am J Transl Res 2015;7:21412158.

8 Peng Z, Wang CX, Fang EH, Wang GB, Tong Q: Role of epithelial-mesenchymal transition in gastric cancer initiation and progression. World J Gastroenterol 2014;20:5403-5410.

-9 Iv Santaliz-Ruiz LE, Xie X, Old M, Teknos TN, Pan Q: Emerging role of nanog in tumorigenesis and cancer stem cells. Int J Cancer 2014;135:2741-2788.

10 Chen SC, Liao TT, Yang MH: Emerging roles of epithelial-mesenchymal transition in hematological malignancies. J Biomed Sci 2018;25:37.

-11 Sengodan SK, K H S, Nadhan R, Srinivas P: Regulation of epithelial to mesenchymal transition by BRCA1 in breast cancer. Crit Rev Oncol Hematol 2018;123:74-82. 


\section{Cellular Physiology Cell Physiol Biochem 2018;50:501-511 \begin{tabular}{ll|l} 
DOI: 10.1159/000494164 & $\begin{array}{l}\text { O 2018 The Author(s). Published by S. Karger AG, Basel } \\
\text { www.karger.com/cpb }\end{array}$ \\
\hline and Biochemistry onlne: II October 2018
\end{tabular}}

Xin et al.: CDC27 Induces EMT via Twist in Gastric Cancer

12 Jie XX, Zhang XY, Xu CJ: Epithelial-to-mesenchymal transition, circulating tumor cells and cancer metastasis: Mechanisms and clinical applications. Oncotarget 2017;8:81558-81571.

13 Link LA, Howley BV, Hussey GS, Howe PH: PCBP1/HNRNP E1 Protects Chromosomal Integrity by Translational Regulation of CDC27. Mol Cancer Res 2016;14:634-646.

14 Ren YQ, Fu F, Han J: MiR-27a modulates radiosensitivity of triple-negative breast cancer (TNBC) cells by targeting CDC27. Med Sci Monit 2015;21:1297-1303.

15 Qiu L, Tan X, Lin J, Liu RY, Chen S, Geng R, Wu J, Huang W: CDC27 Induces Metastasis and Invasion in Colorectal Cancer via the Promotion of Epithelial-To-Mesenchymal Transition. J Cancer 2017;8:2626-2635.

-16 Feng Z, Zhang L, Zhou J, Zhou S, Li L, Guo X, Feng G, Ma Z, Huang W, Huang F: mir-218-2 promotes glioblastomas growth, invasion and drug resistance by targeting CDC27. Oncotarget 2017;8:6304-6318.

17 Lee SJ, Langhans SA: Anaphase-promoting complex/cyclosome protein Cdc27 is a target for curcumininduced cell cycle arrest and apoptosis. BMC Cancer 2012;12:44.

18 Rajkumar T, Gopal G, Selvaluxmi G, Rajalekshmy KR: CDC27 protein is involved in radiation response in squamous cell cervix carcinoma. Indian J Biochem Biophys 2005; 42:271-8.

19 Karlsson MC, Gonzalez SF, Welin J, Fuxe J: Epithelial-mesenchymal transition in cancer metastasis through the lymphatic system. Mol Oncol 2017;11:781-791.

20 Montanari M, Rossetti S, Cavaliere C, D’Aniello C, Malzone MG, Vanacore D, Di Franco R, La Mantia E, Iovane G, Piscitelli R, Muscariello R, Berretta M, Perdonà S, Muto P, Botti G, Bianchi AAM, Veneziani BM, Facchini G: Epithelial-mesenchymal transition in prostate cancer: an overview. Oncotarget 2017;8:35376-35389.

21 Yang YM, Yang WX: Epithelial-to-mesenchymal transition in the development of endometriosis. Oncotarget 2017;8:41679-41689. 